\title{
Creating a 4D Photoreal VR Environment to Teach Civil Engineering
}

\author{
James Walker \\ Dept. of Civil Engineering \\ University of Nottingham Ningbo China \\ Ningbo, China \\ James.Walker@Nottingham.edu.cn \\ Ahmed Elamin \\ Dept. of Civil Engineering \\ University of Nottingham Ningbo China \\ Ningbo, China \\ Ahmed.Elamin@Nottingham.edu.cn
}

\author{
Denis Stepanov \\ School of Computer Science \\ University of Nottingham Ningbo China \\ Ningbo, China \\ Scyds1@Nottingham.edu.cn \\ Matt Pike \\ School of Computer Science \\ University of Nottingham Ningbo China \\ Ningbo, China \\ Matthew.Pike@Nottingham.edu.cn
}

\author{
Dave Towey \\ School of Computer Science \\ University of Nottingham Ningbo China \\ Ningbo, China \\ Dave.Towey@Nottingham.edu.cn \\ Ran Wei \\ Library, Research \& Learning Resources \\ University of Nottingham Ningbo China \\ Ningbo, China \\ Sherry.Wei@Nottingham.edu.cn
}

\begin{abstract}
Motivated by recent developments in AR/VR technology and accessibility, an interdisciplinary team at a Sinoforeign Higher Education Institution in China have been engaged in the creation of a virtual reality learning resource that will be offered to students and educators in the institution's Civil Engineering department. In Civil Engineering education, it is difficult to explain to students how classroom theories translate into real life solutions and field trips can help resolve this problem. However, these must overcome fundamental concerns associated with student site visits, which include safety, logistics and accessibility for disadvantaged students. The presented case study details the development of a virtual field trip that is accessible from simple phone-based virtual reality headsets. The photoreal virtual field trip was constructed through multiple site visits to capture data and the experience now provides students with an opportunity to view the entire construction process of a university library. This paper contributes to current research by exploring the challenges and conjugate solutions encountered whilst building the virtual reality environment, and by presenting the first known photoreal virtual field trip that allows students to autonomously move both spatially and chronologically around a construction site. This will benefit other educational practitioners who are contemplating similar initiatives.
\end{abstract}

Keywords-Virtual reality (VR), virtual field trips (VFTs), higher education, Sino-foreign higher education, student experience, student-centring.

\section{INTRODUCTION}

The recent development of the mainland Chinese economy [1][2] and higher education (HE) sector have been widely studied and reported upon [3]. Sino-foreign HE institutions (SfHEIs) are one aspect of the People's Republic of China (PRC) HE developments, and have been cited as both innovations, and centres for educational innovation and creativity [3]. The University of Nottingham Ningbo China (UNNC), the institution where the activities and events of this paper have been taking place, is one of these SfHEIs.

Motivated by a number of different reasons, an interdisciplinary team at UNNC (the authors of this paper), used the occasion of a new campus library construction to develop a learning object in the form of a virtual field trip.
Some of the initial enthusiasm for this learning object development included the potential to contribute to an open educational resource (OER) [16], [17], [18] that could also facilitate flipping the civil engineering (CE) classroom at UNNC [4]. Much progress has been made, including the completion of a prototype with the corresponding analysis of preliminary student feedback.

The rest of this paper is laid out as follows: Section II introduces the background to the paper, including an assessment of the availability and usability of virtual reality in education. Section III discusses the approach and methodology used in the project, including highlighting some of the key design decisions. Section IV examines the implementation so far, including the user experience and the support provided for group cooperation. Section V reports on some initial user testing of the virtual environment and follows with a discussion on the potential to develop the project as an OER. Finally, Section VI concludes the paper.

\section{BACKGROUND}

This section will introduce the background of the research including an assessment of the availability and usability of virtual reality in education.

\section{A. Virtual Reality Accessibility}

Previous discussions [5] have concluded that computer simulations can be effective pedagogical tools, especially for the teaching of complex concepts. Accordingly, many traditional simulation approaches have evolved into virtual reality (VR) and augmented reality $(\mathrm{AR})$ experiences; where learners have opportunities to interact with computer simulated characters or situations. VR typically involves the use of computer technology to create a simulated environment. It has been deployed with increasing frequency to teach coding, design [6], mathematics [7], geometry [8], the sciences [9], [10] and engineering [11].

VR/AR has not always been accessible to the average student (or teacher). While some have suggested that VR/AR can be traced back to the first stereoscope, invented in 1838 
[5], it was around the mid-1980s when VR equipment such as goggles and gloves began to appear [12]. Such equipment has allowed for the creation of immersive VR systems based on the CAVE concept [see discussions in 13], where the user can move around an environment surrounded by walls with images projected onto them. While the cost of the associated equipment has historically been prohibitively expensive, prices have been dropping significantly. One example includes products such as Google Cardboard, which is a simple cardboard head-mounted display (HMD) that is inexpensive and fits any regular size smartphone [14]. Google Cardboard can be used by a large proportion of the population to experience VR; thereby, making the VR/AR experience affordable to both institutions and individuals. Even the more sophisticated headsets such as those from Oculus and HTC are becoming more common in educational institutions [15].

Although many hardware issues have been resolved for the delivery of teaching through VR/AR, challenges remain related to the content, human-computer interaction (HCI), user experience (UX) and software applications. Currently, there are no sufficiently moderated or curated VR/AR learning materials that could be adopted in the classroom, for engineering, computer science (CS) or other disciplines. The Open Educational Resource (OER) movement [16], [17], [18] has been advocating for more materials and resources with specific editing and sharing rights to support more appropriate teaching and learning material development. Nevertheless, this lack of content is a remaining challenge and a motivator for the work described in this paper.

\section{B. Virtual Reality Usability}

The advancement of learning situated in virtual environments (VEs) introduces a number of $\mathrm{HCI}$ and $\mathrm{UX}$ design issues that must be carefully considered. Navigating and controlling in photorealistic VEs (PVEs) is an example of one interaction design issue that must be considered when developing these experiences. VR experiences typically provide users with an eccentric point-of-view, giving the impression of being immersed within the VE. This is in contrast to traditional 2D gaming environments where the user will "look through a window" onto the game and interact with the environment via an avatar. Reference [19] explored the impact visual realism has on the perception and interaction behaviour of users in VE, concluding that improved visual realism might enhance realistic behavioural response. Similarly, [20] concluded that photorealistic avatars that exhibit behavioural realisms improved the quality of communication in an immersive VE. Realistic environments are key to ensuring that learners remain immersed in the VE and engaged in the learning task.

The design of VEs must also consider learner autonomy. Guided and free-roaming pathways are two opposing approaches towards VE design in PVEs. Traditional game designs typically follow the former, with players being subtly directed through a game map. VR, however, may benefit from a more free-roaming approach allowing learners to identify and discover elements of the intended learning task in a natural and inquisitive manner. Reference [21] details the literature related to supporting autonomy in VREs; key amongst the findings is the ability for VREs to support: (1) reflection and selfawareness during learning; (2) collaboration with peers; and (3) learner-centred learning environments.

Reference [21] also highlights the importance of developing mechanisms for supporting group/shared experiences. Communication amongst group members in a shared VRE introduces a variety of classical HCI problems, including issues of presence, coordination and collaboration. In a group-based VR experience, [22] describes how epistemic scripts have the potential to make learning more efficacious in virtual game environments. The inclusion of scripting introduces a structure and planning to the VE task, providing concrete pathways for learners. However, [21] warns that "Too strict scripting leaves no space for students' own constructions and prevents them from using their full capacity for collaborative learning" highlighting the importance of autonomy and the necessity to collaborate in a learning experience.

A number of studies have documented the impact and causes of VR-induced sickness, and have found that a large proportion of the general population is susceptible. Clearly, such a phenomenon is a major obstacle to the wide scale utilisation of VR as a pedagogical tool. It has been found that the relationship between visual velocity and visual angle of the VE are predominant factors in VR sickness susceptibility [23]. Therefore, VE designers must carefully consider experiences that involve significant or prolonged exposure to motion-based visuals; regular short breaks are recommended.

The evaluation of the HCI and UX in a VRE is a fundamental process that VE designers must complete when delivering an effective environment, and a number of classical HCI approaches can be used, including ethnography, where a researcher observes and questions users as they interact with a VRE. Reference [24] documents the successful application of ethnography to a virtual field trip experience. Similarly, [25] demonstrated the application of applying ethnography to understanding presence (the ability of a communication medium to support communication) in a virtual library setting. Researchers have also proposed the use of quantitative research in evaluating VREs. Reference [26] highlighted the potential benefits and challenges of using direct psychophysiological measures in this context.

\section{Conclusion}

While the development of a VE for teaching is a worthy goal, its implementation may be more difficult than expected. It is necessary to overcome fundamental problems concerning user discomfort because they may prove prohibitive and discourage student engagement. Accordingly, further questions concerning the degree of user autonomy, visual realism, selfawareness and peer collaboration must be considered and imposed. While a deliberative effort can be taken at the design stage, it would appear that an ongoing cycle of implementation and user evaluation is necessary to provide a worthwhile learning experience. 


\section{APPROACH AND METHODOLOGY}

This section will discuss the approach and methodology used in the project, including highlighting some of the key design decisions.

\section{A. Project Overview}

The occasion of the construction of a new campus library at UNNC provided the opportunity to develop content for a new CE experience. Using an aerial drone (a DJI Phantom 4 Pro) and two handheld cameras (an Insta360 Pro and a GoPro Fusion 360), the construction process of a multi-storey library was recorded throughout its development. Using these 'snapshots' of the building's development, a VR experience allowing students to navigate both spatially (around the building) and chronologically (through the different stages of building development) was constructed. The ability to view the stages of the development in a VR environment will enable students to see critical engineering details that are not visible after the building's construction has been completed. Similarly, the safety, affordability and scalability of the VR experience will provide several benefits to CE educators and students.

There remain several pertinent research questions that must be explored to clarify how this VR experience can support student learning in CE. Efforts to answer these questions form the basis of the work presented here and contribute to the body of literature attempting to use virtual experiences to teach students. Broadly, these questions can be condensed into the following themes:

- Data Collection - How best to capture, process and store data for use in these virtual field trip (VFT) style VR experiences?

- Experience Interaction and Group Cooperation - Learning environments are different from many personal or working environments where VR experiences have previously been developed [27] [28]; therefore, it is essential to clarify how learners can be supported in the context of a classroom. This body of investigation includes the use of simultaneous experiences, group interactions and the deployment of the experience in a classroom context.

- Experience Deployment and Evaluation - How can a VR experience be safely, effectively and economically deployed in a HE environment? What does the lifecycle of a VR experience look like? How would it evolve?

- Institutional Concerns - What are institutional attitudes towards such educational resources? What are the practical challenges encountered when deploying these educational experiences? How can these be utilised as an OER?

The present study focuses on the areas of Data Collection, and Experience Interaction and Group Cooperation. A discussion centred on providing solutions to these problems will be described in the following section.

\section{B. Project Approach}

There are multiple software options that are both freely or commercially available that enable the user to create a customised VR tour. Many of these include web development platforms with drag and drop interfaces or open source applications with partial XML coding. In this project, the plan of choosing an appropriate development platform was simplified to include three criteria: it must have documentation or native navigation, have easy access examples and it must accept the institution's hardware requirements. Additional features that were considered advantageous included free licencing and the availability of open source libraries, but these were stated as secondary and desirable features of the platform.

The most appropriate solution was deemed to be the panoramic web development platform operated by the Chinese company '720yun' [29]. This platform allows free online storage hosting for all the images and includes an intuitive interface where a layperson with little coding background could create a panoramic VR tour. There is a drawback with the 720yun platform in that it only has a Chinese language version and it does not support video files. Nevertheless, $720 y u n$ stands as one of the best options to suit the requirements of the current project and can be utilised with an appropriate web plugin translator. Another option that was considered was Pano2Vr [30]; however, this option is not free and it was decided that increased project costs were not justified in this area.

The development of the VR tour required some planning before implementation could proceed. It was required that the hardware captured $360^{\circ}$ images with an aspect ratio of 2:1 in order to be compatible with the software. This is important because if the data collection process has started and the hardware does not capture images that are compatible with the VR software, it may be impossible to edit the pictures rendering them useless.

Finally, while there are multiple available options on the market for $360^{\circ}$ panoramic cameras, the Insta360 Pro was chosen by the authors. While a comparative study was not completed on this issue, the historical experience of the authors (for example, see [31]) together with a competent understanding of the principles of photogrammetry led to the decision to use a six-lens stereoscopic high-definition camera. The Insta360 Pro is accompanied by specific software for automatic stitching of the photos thereby reducing errors associated with parallax.

\section{Project Conditioning}

As explained in Section III-B (Project Approach), building a VR environment using the web development platform $720 y u n$, does not require a background in coding or knowledge in any of the programming languages. Fig. 3.1 provides an example of all of the 720yun functionalities currently available; additional translation has been manually provided by the authors. 


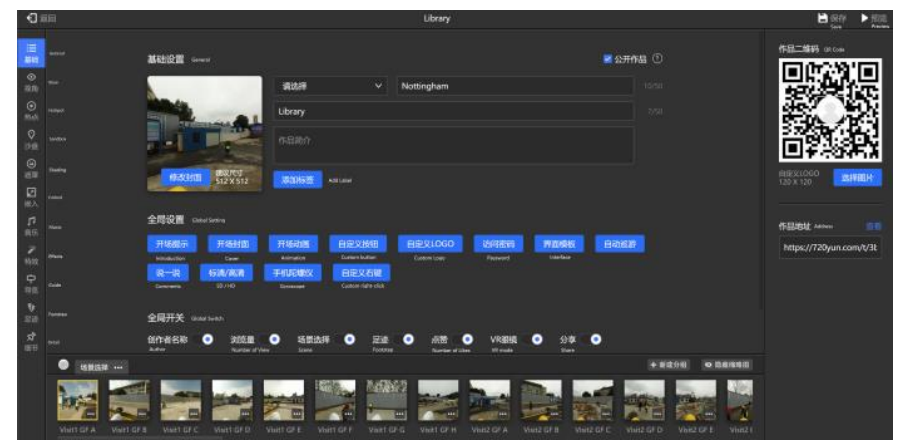

Fig. 3.1. The Main Developer Window with Additional Labels in English

Fig. 3.1 shows the main editor window that a developer will see upon entering the platform. On the left side, there are options to insert specific functions; for example, viewpoints, textbox notes and suggestions. When starting a new project, the photo roll along the bottom of the screen is empty and this is populated when the developer adds images. The panel on the right-hand side shows sharing options for editing purposes, but not for viewing the tour and the central screen provides the main functionality.

During the current VE project, only inherent functions were needed; namely, the perspective choice and checkpoints; these will be described below.

Perspective choice is the option to choose the user's viewpoint when they first enter the tour. In this project, the user's focus was centred on the scene where the main activities took place; an example is presented in Fig. 3.2.

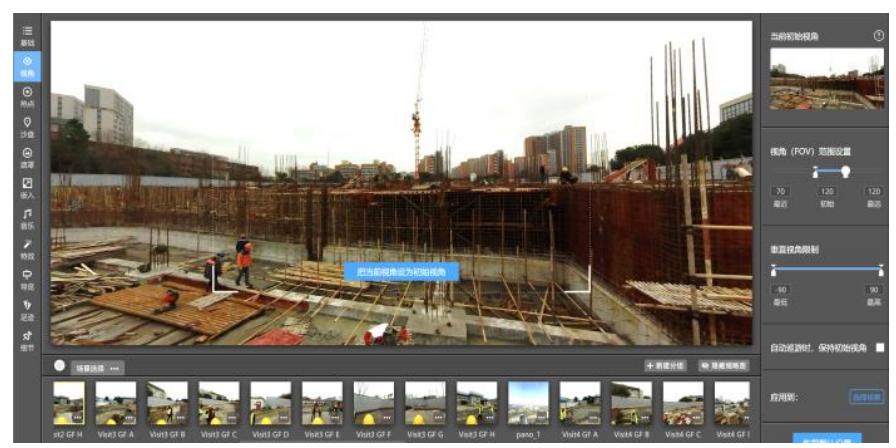

Fig. 3.2. User Viewpoint

The white rectangle shows the specific part of the scene that the user will see upon entry. The 720yun platform provides an option to magnify the view to help the developer focus on details or zoom out for a more general view (all images presented here are shown in their default view).

Implementing viewpoints, commonly referred to as checkpoints, is an important fundamental function in any VR tour. There are 3 different checkpoint types available: default icons, custom icons and drawings; however, only the default icons and custom icons were used in this project. As their name implies, 'default icons' are native to the platform; whereas, 'custom icons' allow the user to upload any desirable ideogram to the platform. When building a project, logical ideograms ought to be used to provide the user with an intuitive experience. Hence, the option for the user to create custom icons was found to be an extremely useful feature that will be discussed in greater detail in Section IV.

Finally, the 720yun platform has a viewer application which can be downloaded from an appropriate mobile phone app store. In the viewer application, there are no options to edit the tour, but the user can view and share the completed VE. One of the most important functions of this platform provides the ability to enter a stereoscopic mode and use a headset to experience the full VFT. An example of the user stereoscopic view is provided in Fig. 3.3.

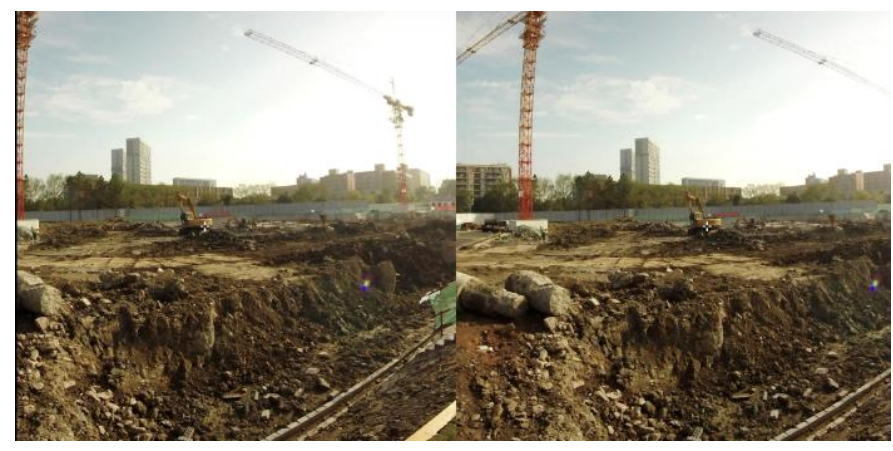

Fig. 3.3. Stereoscopic User Viewpoint

This section has addressed some of the questions that were posed in Section III-A. It can be seen that institutional concerns regarding the cost of the VE are mitigated by using an intuitive free platform that also provides hosting, which also addresses concerns over the longevity of the solution. However, while it is possible to easily find accessible software solutions, it is not prudent save costs on hardware and institutions must decide if the cost of purchasing a high-definition stereoscopic camera is justified. What has not been addressed are questions related to the user experience and group cooperation, and this will be the focus of Section V. Firstly, Section IV will focus on the features that were introduced into this project to complete the development of the VE.

\section{IMPLEMENTATION}

This section will examine the current implementation of the VE including the user experience and the support provided for group cooperation.

\section{A. Navigation}

Implementing a VE UX requires the use of VR headsets. Institutional concerns regarding hardware are often mitigated when costs are minimal and this is of particular concern in the current project because of the requirement that multiple users can enter and use the VE simultaneously. Hence, it was decided to utilise a Google Cardboard type HMD for the purposes of evaluating and testing the environment. No handheld apparatus was used.

The VR tour consists of multiple scenes and each scene has its own checkpoints that allow the user to navigate spontaneously. To complete the project, it was necessary to include five different icons and these are presented in Fig. 4.1. 


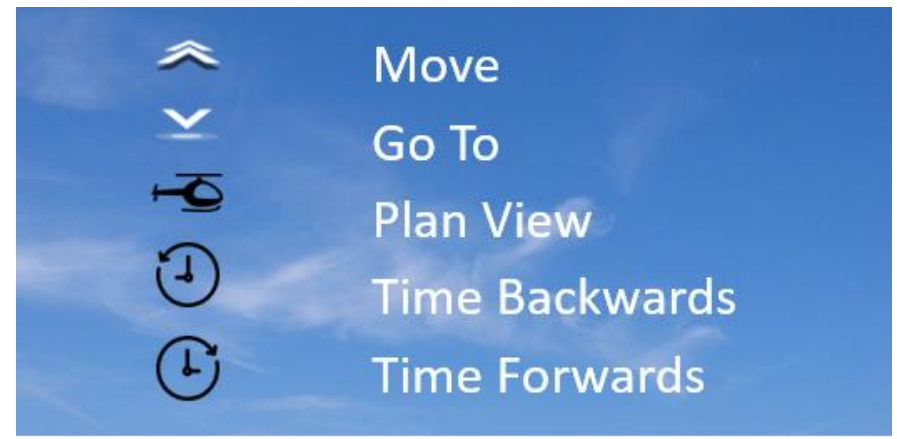

Fig. 4.1 Icons Used in the VE

Fig. 4.1 shows the icons that are used in the VR environment. Both 'Move' and 'Go to' are used to allow the user to spatially navigate around the photoreal virtual construction site. The 'Time Forward' and 'Time Backward' icons allow the user to remain in place and move through the construction process in chronological order. The 'Panoramic View' icons allow the user to enter a plan view and also allow the user to quickly move around the construction site.

The user is able to select these icons by focussing a crosshair on the icon for two seconds. The movement icons are intuitively placed at specific points in the VE indicating where the user can jump to. The Time Forward, Time Backward and Panoramic View icons are placed in the sky; thereby, providing easy access in all photos. To the authors knowledge, this innovative feature is not present in any VE currently available.

\section{B. Panoramic View}

As explained in Section IV-A, the Panoramic View allows the user to enter a bird's eye perspective of the construction site. An example is provided in Fig. 4.2, which shows a plan view of the construction site with eight viewing locations present. Here the labelling convention can be seen, where Visit\# refers to the chronological number of the site visit, GF indicates ground floor and the final letter is used to provide a distinct location coordinate for all viewing locations so that users can communicate their location to other users who may be simultaneously using the VE.

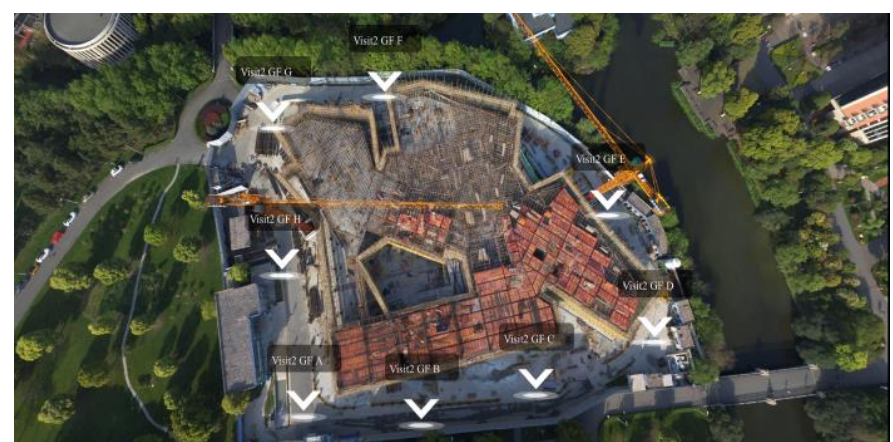

Fig. 4.2 The Elevated Plan View

If the user is not using the elevated plan view, then they will be presented with an image that may be similar to Fig. 4.3.

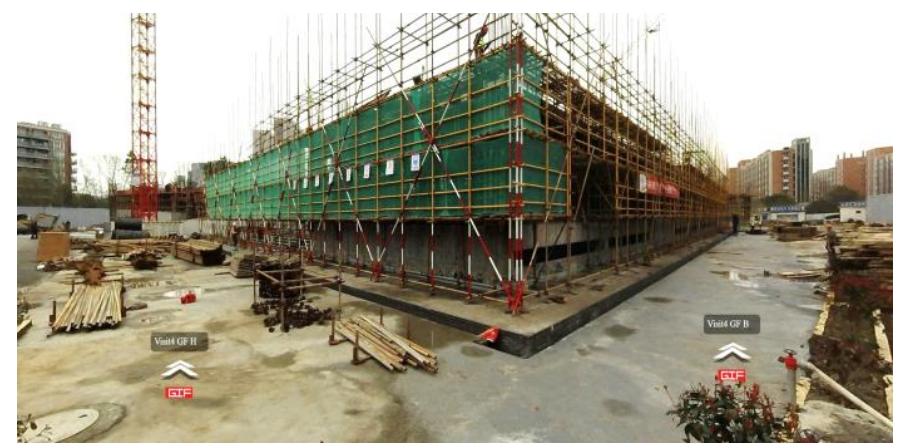

Fig. 4.3 Ground Floor View

Fig. 4.3 shows a ground floor view of the construction site with the arrows indicating the directions of possible movement. While there are eight viewpoints on the perimeter of each site, from each of the ground floor viewpoints, the user can only move in two directions.

An innovative feature of this VE is the inclusion of time. In the following two figures it is possible to see the construction site from the same point, but at different times in the process.

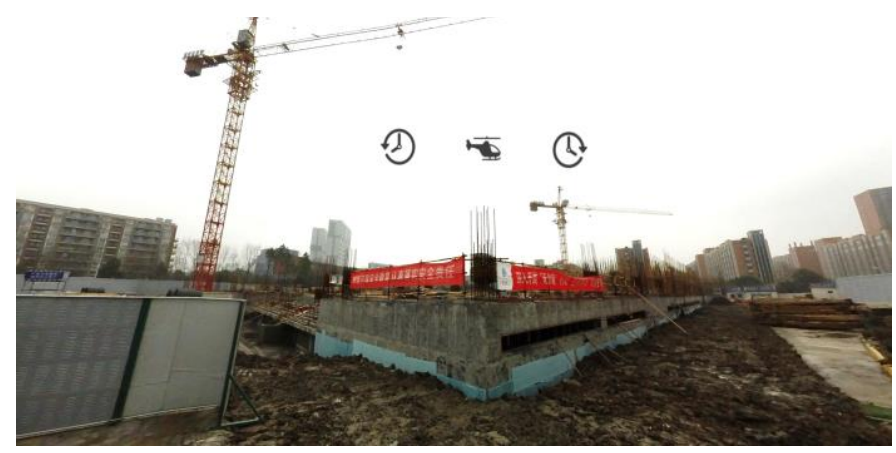

Fig. 4.4. Time Navigation: Early Construction

Fig. 4.4 shows an early part of the construction process when the foundations and basement construction have recently been completed, and the ground floor is being prepared for framing. The icons in the sky are clearly visible and it can be seen that it is a simple process for the user to move through time or move to the elevated plan view taken by the drone. Fig. 4.5 is the same viewpoint at one time point later, which was approximately one month.

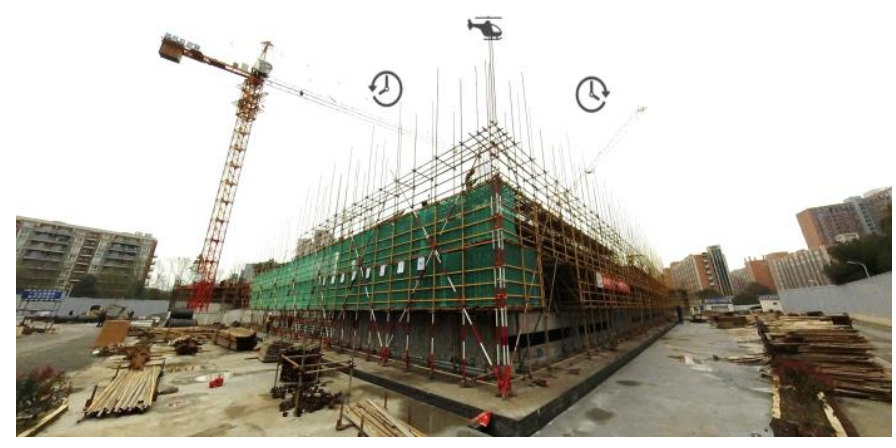

Fig. 4.5. Time Navigation: Later Construction

It can be seen that the users are provided with a degree of flexibility when choosing how to move around the site. They have the ability to view the entire construction process (as 
captured to date) using a free platform, relatively inexpensive equipment and their mobile phones. However, it is important to note that the project did not complete seamlessly and important observations from this experience can be useful for other educators who wish to build their own VEs. An evaluation of this prototype VE is presented in Section V.

\section{Evaluation AND REVIEW}

This section reports on some initial user testing of the virtual environment and follows with a discussion on the potential to develop the project as an OER.

After six visits to the construction site, five engineering students were asked to test the VE using an inexpensive HMD from Park VR [32]. Students were asked to evaluate their experience and provide suggestions for future improvements. The student feedback was coded, grouped and categorised by following the basic principles of discourse analysis. It was found that the feedback could be grouped into three categories: issues with the HMD, feedback on the photos provided and feedback on the information provided to the students surrounding the experience. This feedback will be described in the following sections.

\section{A. Issues with the HMDs}

These issues comprised the most substantial volume of feedback from the students. The aim of the current research investigation was not to evaluate the effectiveness of the HMD, but it was clear that user discomfort was present with all of the students criticising this aspect of the experience. Students had difficulty using the HMDs if they had myopia, and some also experienced discomfort with the nose piece. There was dissatisfaction with the quality of the media presentation (which was attributed to the quality of the lenses in the HMD), and all users experienced problems either adjusting the interpupillary distance or making satisfactory adjustments between their phone and the HMD:

Quite hard to use, couldn't easily find the proper position to place the phone.

Lack of guidance to help students and beginners to adjust the double crosshair which is relative to [the] interpupillary distance

As explained by the students, often this resulted in the appearance of a double crosshair, which impaired the functionality of the system because crosshair focusing is necessary for movement within the VE. Furthermore, three of the students reported dizziness, which either occurred initially and then abated or developed after approximately ten minutes of use. Moving forward, it is clear that a comparative study of different models of HMDs will be necessary to enable this project to be completed successfully.

\section{B. Feedback on the Photoreal Environment}

Four students provided comments on the content used in the VE. Overall reactions were mixed. The ability to 'time travel' was positively received, with students highlighting the opportunities for reflecting on the construction process.
The moveable view and optional time sequence will make it clear for students to understand [how] a construction site works.

Could give a quite direct impression [of] the construction site. Could clearly show the process of construction.

Furthermore, the plan view of the site that was taken by the drone was particularly praised by one student who could see the value of being able to see views from typically inaccessible viewpoints:

...using [a] UAV [for] achieving God's perspective, which is a good experience for students in [a] site visit

However, other students were critical when they perceived that the technology could have been used more intricately:

For civil engineering students, they need to get inside to learn more about the site, like materials and structures.

Some indoor images and some detailed parts, like connections of the beam and column etc.

This was accompanied by suggestions for having videos of the construction site or allowing the users to walk around the site instead of simply being restricted to the hotspots. The result was that some students explained that they would prefer to visit the construction site in real life and that visiting the environment was not a suitable replacement.

\section{Experience Feedback}

Feedback on the entire user experience was mixed. Some students could see value in the enterprise because it is able to provide safe access to construction sites that they might not be able to otherwise see:

Students don't need to go to the real construction site, which would be a little bit dangerous

Engineer can use the system to understand the condition for the site even though [s/he] is far away from the place.

Furthermore, there was some evidence that this VE was able to satisfy some of the project goals:

I think it's an interesting experience, and I actually had learnt something about the construction site by this system.

However, students were also vocal about the shortcomings:

In reality, when students visit site, they will ask some question or extend knowledge about construction.

Will it be possible to achieve interaction of teacher and students in the same VR view? I mean the lecturer could explain all the details in the "construction site"

It is clear that while some students could appreciate the novelty of the VE, the initial awe quickly dissipated and students were then quick to question the value of the exercise. This useful conclusion opens a discussion, which must be centred on how best to answer students' questions and provide information when they are using the VE. 


\section{Open Educational Resource Potential}

The phrase "Open Educational Resources" (OERs) [16], [17], [18] refers to "materials used to support education that may be freely accessed, reused, modified and shared" [18, p.1]. Paralleling the development of open source and "free" software in the 1980s and 1990s, in opposition to propriety software [33], OERs incorporate licensing to ensure that the shared resources remain available to the community [34].

Although the project described in this paper had initial aspirations to develop the learning resource as an OER [5], the various tensions surrounding OER development in the context of UNNC's intellectual property rights policies mean that a number of challenges to this exist [35], [36], [37]. Nevertheless, contributing to the OER community remains a key motivation of this project.

\section{CONCLUSION}

This paper has reported on an initiative at a Sino-foreign higher educational institution, where an interdisciplinary team were motivated to develop an OER in the form of a VFT.

This resource would both alleviate challenges to $\mathrm{CE}$ education that may involve danger and restricted access to construction sites, and would also potentially facilitate classroom flipping. To develop this pedagogical tool, the choice of development software was not arbitrary and after deliberation the research team decided to use the freely available platform, 720yun, because it is relatively feature rich when compared with other freely available online development platforms. To encourage collaborative use of the environment it was designed for hands free use and this project implemented the innovative use of icons floating in the sky to allow users to move through time and access an overhead view.

A prototype was implemented and the initial feedback received from some of the student body within UNNC indicated that they had issues with the HMDs, the content and the lack of teacher assistance; however, there was also some evidence that the project has potential to achieve the stated objectives. It is clear that an appropriate choice of HMD, a greater number of viewpoints placed in internal and subjectively interesting locations together with additional user explanations would increase users' acceptance of the technology for the purpose of creating a field trip that is safe, simple to implement and provides construction site access to disadvantaged students.

\section{ACKNOWLEDGMENTS}

The authors gratefully acknowledge LRLR for lending their equipment and the Ningbo Construction co. Ltd for providing access to their construction site. The authors would also like to thank UNNC for providing a T\&L grant that facilitated equipment upgrades and UNNC's FoSE for providing a T\&L Conference Grant.

\section{REFERENCES}

[1] Y. Li, J. Whalley, S. Zhang, and X. Zhao, "The higher educational transformation of China and its global implications," in C. Ennew and D. Greenaway (eds), The Globalization of Higher Education, Palgrave Macmillan, chapter 10, 2012, pp. 135-162.
[2] D. Towey, "Preparing the next generation of China's computer scientists: A snapshot of challenges for Sino-foreign computer science education," in Proceedings of the Third International Conference on Open and Flexible Education (ICOFE 2016), Jul 2016, pp. 224-231.

[3] D. Towey, "Open and flexible learning as an alternative in mainland Chinese higher education," in Emerging Modes and Approaches in Open and Flexible Education, K. C. Li and K. S. Yuen, Eds. Hong Kong: The Open University of Hong Kong Press, chapter 2, 2014, pp. 12-26.

[4] J. L. Bishop and M. A. Verleger, "The flipped classroom: A survey of the research," in Proceedings of the 2013 ASEE National Conference, Atlanta, GA, 2016, pp. 1-18.

[5] D. Towey, J. Walker, C. Austin, C.F. Kwong and S. Wei (2018), "Developing a Virtual Reality Open Educational Resource in a Sinoforeign Higher Education Institution: Challenges and Strategies," in Proceedings of the IEEE International Conference on Teaching, Assessment, and Learning for Engineering (TALE 2018), pp. 740-746.

[6] Z. Merchant, E. Goetz, W. Keeney-Kennicutt, O. Kwok, L. Cifuentes, and T.J. Davis, "The learner characteristics, features of desktop 3D virtual reality environments, and college chemistry instruction: A structural equation modelling analysis," Computers and Education, vol. 59, no. 2, 2012, pp. 551-568.

[7] M. Kebritchi, A. Hirumi, and H. Bai, "The effect of modern mathematics computer games on mathematics achievement and class motivation," Computers and Education, vol. 55, no. 2, 2010, pp. 427443.

[8] W.-Y. Hwang and S.-S. Hu, "Analysis of peer learning behaviours using multiple representations in virtual reality and their impacts on geometry problem solving," Computers and Education, vol. 62, 2013, pp. 308319.

[9] Z. Merchant. (2014). "Effectiveness of virtual reality-based instruction on students' learning outcomes in K-12 and higher education: A metaanalysis". Computers and Education, 70, pp. 29-40

[10] E. A. Lee, K. W. Wong, and C. C. Fung, "How does desktop virtual reality enhance learning outcomes? A structural modelling equation approach," Computers and Education, vol. 55, no. 4, 2010, pp. 14241442 .

[11] B. D. Coller and D. J. Shernoff, "Video game-based education in mechanical engineering: a look at student engagement," International Journal of Engineering Education, 25, 2009, pp. 308-317.

[12] J. Bown, E. White, A Boopalan, "Chapter 12 - Looking for the ultimate display: A brief history of virtual reality," Editor(s): Jayne Gackenbach, Johnathan Bown, Boundaries of Self and Reality Online, Academic Press, 2017, pp. 239-259.

[13] P. Wang, P. Wu, J. Wang, H.-L. Chi, and X. Wang, "A critical review of the use of virtual reality in construction engineering education and training," International Journal of Environmental Research and Public Health, vol. 15, no. 6, 2018, 1204.

[14] Google. "Google Cardboard." [Online]. Available: https:// vr.google.com/cardboard/ [Accessed: Aug 8 ${ }^{\text {th }}, 2019$ ].

[15] S. Minocha, A. D. Tudor and S. Tilling, "Affordances of mobile virtual reality and their role in learning and teaching," The 31st British Human Computer Interaction Conference, University of Sunderland's St. Peter's Campus, UK, 2017.

[16] UNESCO and Commonwealth of Learning, "Guidelines for Open Educational Resources (OER) in Higher Education," UNESCO, Paris, France, 2015.

[17] UNESCO, "Forum on the Impact of Open Courseware for Higher Education in Developing Countries: Final Report," Paris, France, 2002.

[18] UNESCO, "2012 Paris OER Declaration”, UNESCO, Paris, France, 2012.

[19] M. Slater, Khanna, P., Mortensen, J., and Yu, I. (2009). "Visual realism enhances realistic response in an immersive virtual environment," IEEE computer graphics and applications, 29(3), pp. 76-84.

[20] M. Garau, M. Slater, V. Vinayagamoorthy, A. Brogni, A. Steed and M.A. Sasse, "The impact of avatar realism and eye gaze control on perceived quality of communication in a shared immersive virtual environment," in Proceedings of the SIGCHI conference on Human factors in computing systems, 2003, pp. 529-536. 
[21] K. Schwienhorst, "Why virtual, why environments? Implementing virtual reality concepts in computer-assisted language learning," Simulation and Gaming, 33(2), 2002, pp. 196-209.

[22] R. Hamalainen, "Designing and evaluating collaboration in a virtual game environment for vocational learning," Computers and Education, 50(1), 2008, pp. 98-109.

[23] N. Tanaka and H. Takagi, "Virtual reality environment design of managing both presence and virtual reality sickness," Journal of physiological anthropology and applied human science, 23(6), 2004, pp. 313-317.

[24] N. Green, "Disrupting the field: Virtual reality technologies and "multisited" ethnographic methods," American Behavioral Scientist, 43(3), 1999, pp. 409-421.

[25] A. Spagnolli, D. Varotto, and G. Mantovani, "An ethnographic, actionbased approach to human experience in virtual environments," International Journal of Human-Computer Studies, 59(6), 2003, pp. 797-822.

[26] M. Pike and E. Ch'ng, "Evaluating virtual reality experience and performance: a brain based approach," in Proceedings of the 15th ACM SIGGRAPH Conference on Virtual-Reality Continuum and Its Applications in Industry, 1, 2016, pp. 469-474.

[27] D. A. Guttentag, "Virtual reality: Applications and implications for tourism," Tourism Management, 31(5), 2010, pp. 637-651.

[28] P. L. Weiss and A. S. Jessel, "Virtual reality applications to work," Work, 11(3), 1998, pp. 277-293

[29] 720YUN. [online] Available https://720yun.com/ [Accessed: Aug $8^{\text {th }}$, 2019]
[30] Garden Gnome Software e.U. "Pano2VR" [online] Available: https://ggnome.com/pano2vr [Accessed: Aug 8 $\left.{ }^{\text {th }}, 2019\right]$

[31] J. Walker, D. Towey, S. Wei, M. Pike, G. Kapogiannis and A. Elamin. "Incorporating Pedagogical Theory into VR to Teach Civil Engineering," in Proceedings of the 2019 International Conference on Open and Innovative Education (ICOIE 2019). Hong Kong, pp. 610621.

[32] VRPARK [Online]. Available: https://detail.tmall.com/item.htm?id=563620497207andspm=a1 z09.2.0.0 $.215 \mathrm{~b} 2 \mathrm{e} 8 \mathrm{dePqQrWand}$ u=9k2gc2ic3af [Accessed: Aug $8^{\text {th }}, 2019$ ].

[33] R. M. Stallman, Free Software, Free Society: Selected Essays of Richard M. Stallman, 2nd ed., Boston, Massachusetts: GNU Press, 2010.

[34] D. Wiley, "The Access Compromise and the 5th R," Iterating Toward Openness, $2014 \quad$ [Online]. Available: https://opencontent.org/blog/archives/3221. [Accessed: 27-Jul-2019].

[35] D. Towey, D. Foster, F. Gilardi, C. Goria, P. Martin and A. White, "Researching and Supporting Student Note-taking: Building a Multimedia Note-taking App," in Proceedings of the IEEE International Conference on Teaching, Assessment, and Learning for Engineering (TALE), 2015, pp.54-58.

[36] T. Wang and D. Towey, "Open Educational Resource (OER) Adoption in Higher Education: Challenges and Strategies," in Proceedings of the IEEE International Conference on Teaching, Assessment, and Learning for Engineering, 2017, pp.317-319.

[37] D. Towey, D. Foster, F. Gilardi, P. Martin, A. White, Y. Jiang, Y. Pan and Y. Qu, "Developing an Open Educational Resource: Reflections on a Student-staff Collaboration," in Proceedings of the 41st IEEE Annual Computer Software and Applications Conference, COMPSAC 2017, Torino, Italy, July 4-8, 2017, pp.707-711. 